\title{
Redifferentiation of Radioiodine Refractory Differentiated Thyroid Cancer for Reapplication of I-131 Therapy
}

\author{
Chae Moon Hong and Byeong-Cheol Ahn* \\ Department of Nuclear Medicine, Kyungpook National University School of Medicine and Hospital, Daegu, South Korea
}

Although most differentiated thyroid cancers show excellent prognosis, treating radioiodine refractory differentiated thyroid cancer (RR-DTC) is challenging. Various therapies, including chemotherapy, radiotherapy, and targeted therapy, have been applied for RR-DTC but show limited effectiveness. Redifferentiation followed by radioiodine therapy is a promising alternative therapy for RR-DTC. Retinoic acids, histone deacetylase inhibitors, and peroxisome proliferator-activated receptor-gamma agonists are classically used as redifferentiation agents, and recent targeted molecules are also used for this

OPEN ACCESS

Edited by:

Veronica Vella,

Kore University of Enna, Italy

Reviewed by:

Paula Soares,

University of Porto, Portugal

Yuji Nagayama,

Nagasaki University, Japan

*Correspondence:

Byeong-Cheol Ahn abc2000@knu.ac.kr

Specialty section: This article was submitted to Cancer Endocrinology, a section of the journal

Frontiers in Endocrinology

Received: 10 August 2017 Accepted: 20 September 2017

Published: 12 October 2017

Citation:

Hong CM and Ahn BC (2017) Redifferentiation of Radioiodine

Refractory Differentiated

Thyroid Cancer for Reapplication

of 1 -131 Therapy.

Front. Endocrinol. 8:260.

doi: 10.3389/fendo.2017.00260 purpose. Appropriate selection of redifferentiation agents for each patient, using current knowledge about genetic and biological characteristics of thyroid cancer, might increase the efficacy of redifferentiation treatment. In this review, we will discuss the mechanisms of these redifferentiation agents, results of recent clinical trials, and promising preclinical results.

Keywords: redifferentiation, differentiated thyroid cancer, I-131, radioiodine refractory, NIS

\section{INTRODUCTION}

Radioiodine has been used for diagnosing and treating differentiated thyroid cancer (DTC) for more than 70 years. The sodium iodine symporter (NIS) plays a critical role in radioiodine accumulation in DTC cells. The NIS is a membrane glycoprotein that transports two sodium ions and one iodide ion into the cytosol of benign and tumorous thyroid cells from extracellular fluid (1-3). Since radioiodine also can be taken up by the NIS, radioiodine can be used to visualize or selectively kill DTC cells.

Until now, I-131 therapy has been the first-line treatment for unresectable radioiodine-avid metastatic DTC, and radioiodine uptake is a good prognostic marker $(4,5)$. However, poorly DTC or anaplastic thyroid cancer cells do not express the NIS, and some DTC cells lose expression of the NIS with disease progression (6). Although most patients with thyroid cancer show good prognosis, $1-4 \%$ of the patients show distant metastasis at initial diagnosis and $7-23 \%$ of the patients show distant metastasis during follow-up periods $(7,8)$. One-third of metastatic DTC patients do not accumulate radioiodine, and two-thirds of metastatic DTC cases become radioiodine refractory DTC (RR-DTC) $(4,5,9,10)$.

ATA 2015 guideline suggested following criteria as definition of structurally evident RR-DTC: (i) the malignant/metastatic tissue does not concentrate radioiodine; (ii) the tumor tissue loses the ability to concentrate RAI after previous evidence of radioiodine-avid disease; (iii) radioiodine is 
concentrated in some lesions but not in others; and (iv) metastatic disease progresses despite significant concentration of radioiodine (11). However, there are some differences of detail definitions of RR-DTC according to the researchers, such as number of previous radioiodine therapy, cumulative dose of radioiodine, FDG avidity of the lesion, and so on (12-14). The trivial discrepancy about the definition of RR-DTC originates from generation of the clinical view point, and it can be modified in the future by following clinical experiences.

Radioiodine refractoriness is mainly related to the NIS expression of the thyroid cancer cells. And the ability to concentrate radioiodine is generally considered to indicate a more differentiated phenotype. Inverse relationship between radioiodine and FDG uptake also suggests that the positive correlation between differentiation and radioiodine uptake of the tumor (10). Recent advance of the cancer genetics showed major mutation of papillary thyroid cancer: BRAF V600E accounts for $60 \%$, RAS for $15 \%$, and receptor tyrosine kinase (RTK) for $12 \%$ (15). And these RTK and mitogen-activated protein kinase (MAPK) pathway plays a major role in expression of thyroid-specific genes, including NIS (Figure 1). Many other studies also suggested that radioiodine refractoriness is related to MAPK pathway activation $(16,17)$. Therefore, signaling proteins of the pathway are considered as new targets for redifferentiation.

For RR-DTC, no curative treatment modality is currently available, except complete surgical excision which is not always possible. Usually, RR-DTCs are also refractory to external radiotherapy or chemotherapy (18). Targeted therapies, such as tyrosine kinase inhibitor (TKI) treatment, have emerged as new treatment modalities for RR-DTCs. The Food and Drug Administration of United States and European Medical Agency approved sorafenib and lenvatinib for the treatment of RR-DTCs $(13,14)$. However, the challenges of using TKI drugs are maintaining the continuous use of these drugs and managing their adverse effects (19). Although many phase III clinical trials on these drugs showed improved progression-free survival and objective response rate, only limited overall survival gains were achieved $(13,14)$. The escape phenomenon and resistance are other common limitations of TKIs (20).

Redifferentiation therapy followed by I-131 therapy is an alternative option for RR-DTC patients. Previous studies suggested that several compounds such as retinoic acid (RA), MEK/ERK inhibitors, PPAR $\gamma$ agonists, histone deacetylase (HDAC) inhibitors, and phosphatidylinositol 3-kinase (PI3K)/AKT inhibitors have the potential to redifferentiate RR-DTC. Treatment with these compounds resulted in increased radioiodine uptake by enhanced NIS expression in DTC (18), and recent clinical trials showed promising results of redifferentiation therapy followed by I-131 therapy $(12,21)$. In this review, we will discuss the basic underlying mechanisms of each redifferentiation therapy and results of recent clinical trials and promising preclinical results.

\section{RETINOIC ACID}

Retinoic acid is a well-known drug for certain dermatological diseases and has been also used as a redifferentiation agent for hematological malignancies and thyroid cancer for more than
20 years. RA is a metabolite of vitamin A that binds to nuclear receptors designated as RA receptors (RAR) or retinoid $\mathrm{X}$ receptors (RXR) (18). RA-RAR or RA-RXR complexes bind to the responsive elements in gene promoter sites and activate the transcription of their target genes. RA is related to cellular differentiation, proliferation, and apoptosis, and induces the redifferentiation and expression of NIS genes in thyroid cancer cells (22). Therefore, radioiodine uptake and thyroglobulin production by thyroid cancers are increased by RA treatment (23).

For dedifferentiated thyroid cancers that show no radioiodine uptake, RA has been used as an alternative treatment. Simon et al. performed the first clinical trial of RA treatment, and observed the renewed uptake of radioiodine in 4 of 10 patients with RR-DTC (24). Other early clinical trials also reported that about $40-50 \%$ of patients with RR-DTC showed increased radioiodine uptake (25-27). Fernandez et al. reported that 9/27 (33\%) showed optimal radioiodine uptake in metastatic lesions, and 10/27 (37\%) showed suboptimal radioiodine uptake after RA treatment. Among them, 4/9 (44\%) of optimal uptake group and 3/10 (30\%) suboptimal uptake group showed partial response (PR) or stable disease (SD) (28). Oh et al. reported that 19/47 (40.4\%) of patients showed a treatment response [1 complete response (CR), $9 \mathrm{PR}$, 9 SD] (29).

However, response to I-131 therapy after RA pretreatment did not always correlate with increased radioiodine uptake (27). And subsequent studies showed disappointing results, with only $6-20 \%$ of patients showing increased radioiodine uptake upon RA pretreatment $(23,30-33)$, several studies did not find any clinical value of I-131 therapy after RA pretreatment in patients with RR-DTC $(31,33)$.

As most of the studies were performed using 13-cis-RA, alltrans-RA, and bexarotene (RXR activator) were also applied for redifferentiation and showed good results (18). Zhang et al. used all-trans-RA and reported that radioiodine uptake was increased in 4/11 patients and 7/11 patients showed a response (5 PR, 2 SD) (34). In addition to increasing radioiodine uptake, all-trans RA may suppress cell proliferation by activating pro-apoptotic pathways or directly influencing the cell cycle $(35,36)$, increased uptake of radioiodine was not necessarily accompanied by reductions of tumor sizes (34). Liu et al. reported that bexarotene (RXR activator) induced radioiodine uptake in $8 / 11$ patients, but no significant therapeutic effectiveness was demonstrated (37).

The controversy about the effect of RA might be associated with the relatively small number of subjects and heterogeneous molecular features of enrolled tumors. Recently, genetic and molecular analyses (such as tests for BRAF, RET/PTC, and RAS, among others) revealed diverse molecular characteristics of thyroid cancers, but most clinical trials applying RA did not analyze these factors. Therefore, more studies are required to unravel the values of RA pretreatment for I-131 therapy in RR-DTC and specific indications for RA-pretreated radioiodine therapy can be developed by these studies.

\section{HDAC INHIBITOR}

Histone deacetylase is an enzyme that deacetylates histones, which results in tightly bound DNA, and silences gene expression. 


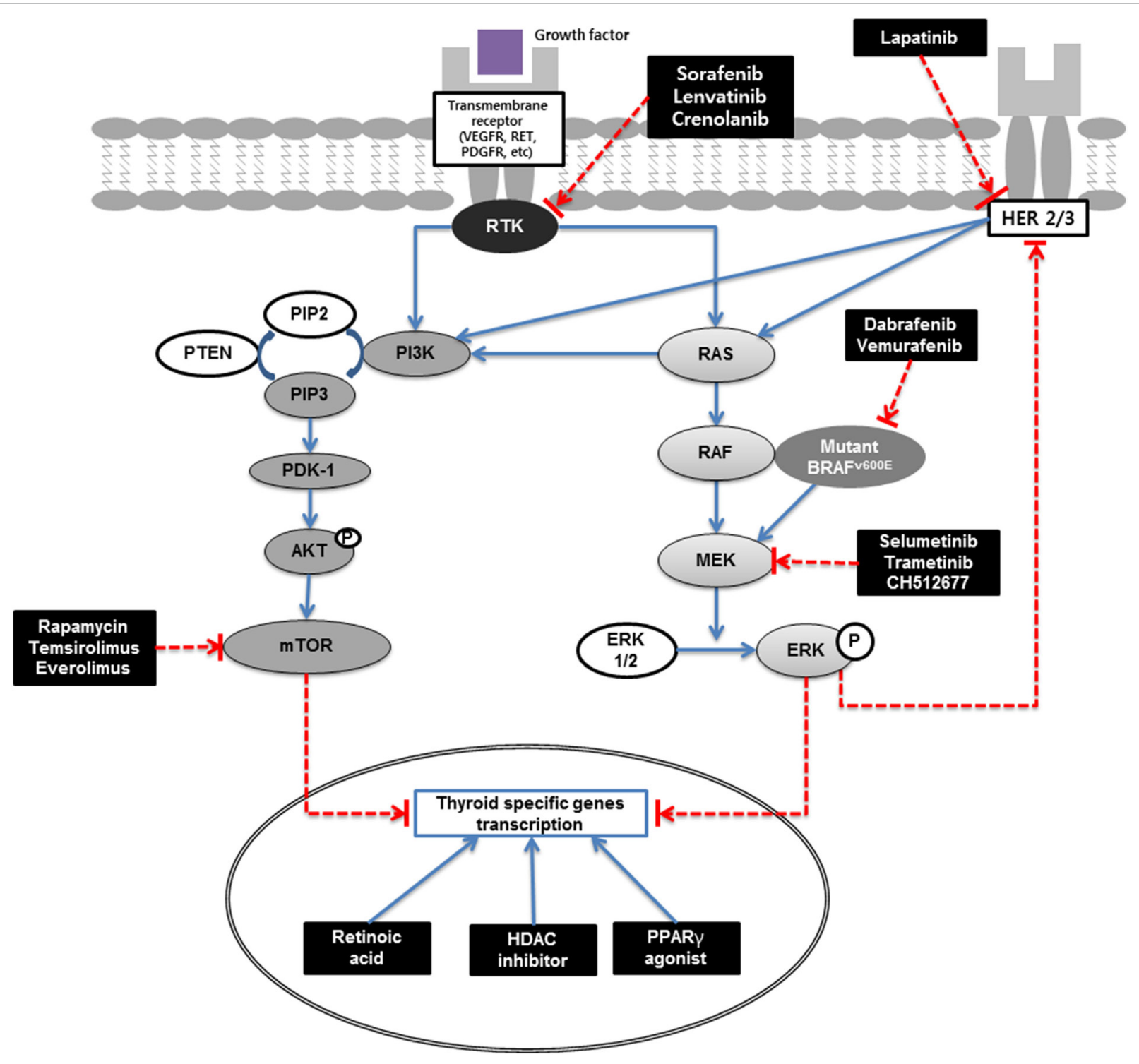

FIGURE 1 Redifferentiation of thyroid cancer schematic. MAPK (RAS/RAF/MEK) and PI3K/AKT/mTOR pathways are main signaling pathways in thyroid carcinogenesis. Extracellular signals activate RTK and RAS, which in turn activates RAF (mainly BRAF in differentiated thyroid cancer). Activated BRAF phosphorylates and activates the MEK, which in turn phosphorylates and activates ERK. Phosphorylated ERK translocate into the nucleus, where it regulates transcription of the genes involved in cell differentiation, proliferation, survival, and thyroid-specific genes transcriptions. PI3K/AKT activates mTOR which is a key regulator of cell proliferation, inhibitor of apoptosis, and thyroid-specific genes transcriptions. Signaling cascade can be blocked by new targeted therapies. RA binds to nuclear receptors designated as RA receptors (RAR) or retinoid X receptors (RXR). PPAR $\gamma$ agonists bind to RXR and form heterodimers and regulate the transcription of various genes. RAR or RXR complexes bind to the responsive elements in gene promoter sites and activate the transcription of their target genes. HDAC is an enzyme that acetylates histone and silences gene expression; HDAC inhibitors increase gene expression at an epigenetic level. RTK, receptor tyrosine kinase; VEGFR, vascular endothelial growth factor receptor; RET, rearranged during transfection; PDGFR, platelet-derived growth factor receptors; HER, human epidermal growth factor receptor; PI3K, phosphoinositide 3-kinase; PIP2, phosphatidylinositol 4,5-bisphosphate; PIP3, phosphatidylinositol (3,4,5)-trisphosphate; PTEN, phosphatase and tensin homolog; PDK-1, pyruvate dehydrogenase lipoamide kinase isozyme 1; AKT, protein kinase B; mTOR, mechanistic target of rapamycin; RAS, rat sarcoma; RAF, rapidly accelerated fibrosarcoma; MAPK, mitogen-activated protein kinase kinase; ERK, extracellular signal-regulated kinase; HDAC, histone deacetylase; PPAR $\gamma$, peroxisome proliferator-activated receptor $\gamma$.

HDAC inhibitors increase gene expression at an epigenetic level. In thyroid cancer, HDAC inhibitor treatment is expected to induce redifferentiation by increasing the expression of thyroid-specific genes such as those for thyroid peroxidase and NIS. In addition, HDAC inhibitor treatment also reduces the proliferation rate of thyroid cancer cells and induces apoptosis (38). Previous preclinical studies showed increased radioiodine uptake by pretreatment with various HDAC inhibitors, such as depsipeptide (romidepsin) (39-41), trichostatin A (42), valproic acid (43), sodium butyrate (44), and suberoylanilide hydroxamic acid (SAHA) (45). 
However, clinical trials on HDAC inhibitors for RR-DTC patients yielded disappointing results. Kelly et al. used SAHA in various malignancies, and six metastatic thyroid cancer patients were included (46). In the clinical trial, three patients underwent radioiodine scan, and one patient (33\%) showed increased radioiodine uptake by SAHA pretreatment. AmiriKordestani et al. performed a phase I clinical trial using romidepsin in $11 \mathrm{RR}-\mathrm{DTC}$ patients, but follow-up radioiodine scans did not show a meaningful increase in radioiodine uptake (47). Sherman et al. performed a phase II clinical trial to evaluate the effect of romidepsin in 20 patients with RR-DTC, but only $2 / 20(10 \%)$ patients showed restored radioiodine uptake and no major response was observed (48). Nilubol et al. performed a phase II clinical trial of valproic acid in RR-DTC patients, but valproic acid did not increase radioiodine uptake in tumors (49).

\section{PPAR $\gamma$ AGONIST}

Peroxisome proliferator-activated receptor $\gamma(\operatorname{PPAR} \gamma)$ is a nuclear receptor that forms a heterodimer with RXR and regulates the transcription of various genes, such as those involved in adipogenesis, inflammation, cell cycle control, and apoptosis. The thiazolidinediones, also known as glitazones, which are used to treat diabetes mellitus, are PPAR $\gamma$ agonists. Previous studies showed that PPAR $\gamma$ mRNA is downregulated in papillary thyroid cancer cells compared to the normal thyroid tissue, benign nodule, follicular and anaplastic thyroid cancers (50, 51). Various thiazolinediones showed therapeutic effect for DTC, especially PPAR $\gamma$ overexpressing cancers (50-52).

PPAR $\gamma$ agonists also redifferentiate thyroid cancer cells. Frohlich et al. reported that troglitazone increased NIS expression and radioiodine uptake (53). Park et al. also observed upregulation of NIS mRNA after troglitazone treatment in papillary, follicular, and anaplastic thyroid cancer cells (54). Based on these studies, several clinical trials using PPAR $\gamma$ agonists were performed for RR-DTC. Philips et al. performed a clinical trial using rosiglitazone and observed increased thyroglobulin production but only 1/5 (20\%) patient showed faint radioiodine uptake (55). Kebebew et al. reported that 5/20 (25\%) patients showed positive radioiodine uptake after rosiglitazone treatment, but this radioiodine uptake did not result in a clinically significant response to RR-DTC on long-term follow-up and there was no reduction in tumor size, as revealed by anatomical imaging studies (56).

The results of early clinical trials using PPAR $\gamma$ agonists were not satisfactory, but several studies showed the possibility of better clinical results when specific patient groups were enrolled. Tepmongkol et al. treated 23 patients with RR-DTC with rosiglitazone. Five $(71 \%)$ of 7 patients with strong PPAR $\gamma$-positive staining in biopsy, $1 / 9(11 \%)$ patients with weak staining, and $0 / 7$ $(0 \%)$ patients with negative staining showed tumoral radioiodine uptake upon treatment (57). On the contrary, another study showed that there was no relationship between PPAR $\gamma$ expression and effectiveness of PPAR $\gamma$ agonist treatment $(54,58)$. This inconsistency could have arisen because tumor tissue samples might not exactly represent the tumor, as DTC can contain heterogeneous cell populations and genetic alterations.
A chromosomal rearrangement of the PAX8 gene with PPAR $\gamma$ (PAX8-PPAR $\gamma$ ) is observed in about $36-50 \%$ of follicular thyroid cancer cases (59-61) and $0.8 \%$ of papillary thyroid cancer (15). The PAX8-PPAR $\gamma$ rearrangement is related to the loss of the tumor suppressor function of wild-type PPAR $\gamma$; however, the mechanism is not fully understood yet. Dobson et al. showed promising results that a PPAR $\gamma$ agonist (pioglitazone) was highly therapeutic and prevented metastasis in mice with thyroid-specific expression of PAX8-PPAR $\gamma$ fusion protein (PPFP) and homozygous deletion of phosphatase and tensin homolog (PTEN) (62). Based on these data, a phase II clinical trial of pioglitazone in RR-DTC that contain the PPFP was started (NCT01655719). As pioglitazone was already approved by FDA and has a better toxicity profile than other targeted agents, such as TKIs, positive results of the trial would indicate that pioglitazone may be a good therapeutic option for patients with RR-DTC (63).

\section{MAPK PATHWAY INHIBITORS}

Recent studies using drugs that selectively inhibit the MAPK pathway showed promising results for restoring radioiodine uptake in RR-DTC $(12,16,21)$. NIS expression and radioiodine uptake were markedly decreased in response to inducible expression of a BRAF mutation in a mouse model (16). This study also revealed re-expression of NIS and radioiodine uptake after treatment with a MEK inhibitor (16).

Ho et al. published results of a phase II clinical trial using selumetinib, a selective MEK inhibitor, in RR-DTC patients (12). In their study, increased I-124 uptake was observed in 12 of 20 patients with RR-DTC upon pretreatment with selumetinib. They estimated absorbed doses of target lesions using I-124 PET/CT scans, and 8 of these 12 patients achieved appropriate radioiodine uptake to perform a radioiodine therapy (up to $11 \mathrm{GBq}$ ). Among them, five patients showed PR to the radioiodine therapy (four with NRAS mutations and one with BRAF mutation). In this study, five patients with NRAS mutations and nine patients with BRAF mutations were included. In patients with a BRAF mutation, 4/9 patients showed increased iodine uptake, but only 1/9 patient showed optimal increase of I-124 uptake and revealed PR after the radioiodine therapy. However, every patient with an NRAS mutation achieved sufficient I-124 uptake to proceed with the radioiodine therapy and $4 / 5$ patients revealed $P R$ by the radioiodine therapy. The effectiveness of selumetinib for recovering radioiodine avidity in RR-DTC was higher in patients with an NRAS mutation than in those with a BRAF mutation.

A recent trial using dabrafenib, a selective BRAF inhibitor, showed restoration of radioiodine uptake in RR-DTC (21). This trial was performed for patients with BRAF-mutant RR-DTC. Six of 10 patients $(60 \%)$ developed radioiodine uptake after treatment of dabrafenib. This study did not perform a dosimetric analysis, and they applied an empirical fixed-dose treatment (5.5 GBq). Six months later, five of the six treated patients showed a reduced size of the target lesions by CT imaging (two PR, three SD). Although dabrafenib treatment showed better results than selumetinib treatment in patients with BRAF-mutated RR-DTC, dabrafenib 
still showed relatively poorer response than selumetinib for NRAS-mutated RR-DTC.

The discordant result observed between patients with RASmutated and BRAF-mutated DTCs might be associated with the different amount of activation of the MAPK pathway. The higher MAPK activation is related to the lower expression of NIS. BRAF-mutated DTCs showed higher MAPK activation and lower expression of NIS than RAS-mutated DTCs $(16,17)$. BRAFmutated cancers and those that were positive for FDG uptake are often refractory to radioiodine therapy $(10,64)$. BRAF-mutated papillary thyroid cancers showed lower expression of thyroidspecific genes, which are related to iodine accumulation, than RAS-mutated papillary thyroid cancers (15). Since BRAF mutation suppresses the expression of these genes and inhibits radioiodine uptake (Figure 1), RAF or MEK inhibitors can partially restore the response to radioiodine therapy $(16,17)$. Another explanation for the poor outcomes of BRAF-mutated DTC is the rebound of MAPK signaling after treatment with BRAF or MEK inhibitors (65).

Based on the promising results of preliminary selumetinib treatment (12), the SEL-I-METRY trial (EudraCT no. 2015002269-47) was initiated to confirm the previous results. This multicenter phase II single-arm study will recruit 60 RR-DTC patients. Pretreatment biopsy and baseline I-123 SPECT/CT will be performed, followed by 4 weeks of selumetinib administration. Then, I-123 SPECT/CT will be performed again to determine the changes of radioiodine accumulation in RR-DTC and to evaluate radioiodine tumor dosimetric analysis. Patients who are considered suitable for radioiodine therapy will receive 5.5 GBq I-131. A further series of post-therapy SPECT/CT scans will be performed to calculate the absorbed dose. The primary endpoint for this trial is progression-free survival at 12 months in RR-DTC patients. Exploratory analyses will include lesional dosimetry; examination of BRAF, RET, and RAS mutation status and protein-bound iodine as potential biomarkers; and quality of life. If SEL-I-METRY demonstrates clinical benefits of this treatment schedule, a phase III trial comparing this strategy with other emerging treatment options will be considered (66).

The appropriate I-131 dose can be determined by empiric and dosimetric approaches, and until now, the superiority of one approach over the other is under debate $(67,68)$ regarding whether I-123/I-131 SPECT/CT or I-124 PET/CT provides more valuable results to calculate lesion dosimetry (69-71). Ho et al. used I-124 PET/CT for dosimetric analysis (12), but Rothenberg et al. used a fixed-dose approach (21). As I-124 is not available in many hospitals, SPECT/CT could be more commonly used for dosimetric analysis. Studies that compare the effectiveness of empiric and lesional dosimetry to determine the dose of I-131 after redifferentiation treatment are also needed.

Two other randomized, placebo-controlled clinical trials have been initiated in United States. The ASTRA study was designed to determine whether selumetinib followed by I-131 therapy prevents disease recurrence following initial surgery in patients with high-risk DTC (NCT01843062). The other clinical trial aims to determine the response rate at 6 months following treatment with I-131 in combination with placebo or selumetinib for radioactive iodine-avid recurrent and/or metastatic thyroid cancer (NCT02393690). These two studies focus on increasing the effectiveness of I-131 therapy and might dramatically alter future radioiodine therapy paradigms. Moreover, a short duration of TKI treatment before I-131 therapy might reduce costs and toxicity by enhancing therapeutic effectiveness (72).

\section{PRECLINICAL PROMISING TARGETS FOR REDIFFERENTIATION}

As previously mentioned, many targets for redifferentiation of RR-DTC have been suggested (Table 1), but no CR has been observed yet. Therefore, many researchers are trying to figure out new targets of redifferentiation in RR-DTC.

Receptor tyrosine kinase is one of the key regulators of redifferentiation. Recently developed targeted agents are targeting this RTK family, including vascular endothelial growth factor receptor, rearranged during transfection (RET), plateletderived growth factor receptors (PDGFRs), human epidermal growth factor receptor (HER), and so on. Recently developed targeted agents for RTK are applied for redifferentiation of RR-DTCs. Lopez-Campistrous et al. found an inverse relationship between PDGFR $\alpha$ activation and the transcriptional activity of thyroid transcription factor-1 (TTF1). As TTF1 promotes NIS expression, PDGFR $\alpha$ blockade restored NIS expression (73).

Silenced NIS gene in RR-DTC is associated with activation of the MAPK pathway, which is frequently related with the BRAF V600E mutation (17). Therefore, selective BRAF and MEK inhibitors have been applied to redifferentiation and to enhance radioiodine uptake in RR-DTC $(12,74)$, but rebound MAPK

TABLE 1 | Redifferentiation target mechanism and candidate drugs.

\begin{tabular}{ll}
\hline $\begin{array}{l}\text { Target mechanism of } \\
\text { redifferentiation }\end{array}$ & Candidate drugs \\
\hline Modulating gene transcription & \\
RA & $\begin{array}{l}13 \text {-cis-RA, all-trans-RA, bexarotene } \\
\text { (RXR activator) } \\
\text { HDAC inhibitor }\end{array}$ \\
& $\begin{array}{l}\text { Depsipeptide (romidepsin), trichostatin } \\
\text { curcumin }\end{array}$ \\
PPAR $\gamma$ & $\begin{array}{l}\text { Thiazolidinediones (glitazone; troglitazone, } \\
\text { rosiglitazone, pioglitazone) }\end{array}$
\end{tabular}

\section{MAPK pathway}

RAF

MEK

Dabrafenib, vemurafenib

Receptor tyrosine kinase

PDGFR $\alpha$

HER3

Selumetinib, trametinib, CH5126766 (CKI)

Autophagy activator

PTEN

mTOR

Intracellular calcium

Crenolanib

Lapatinib

Antisense-miR-21

Rapamycin, temsirolimus, everolimus

Digitalis-like compound, curcumin

$R A$, retinoic acid; $R X R$, retinoid $X$ receptor; HDAC, histone deacetylase; SAHA, suberoylanilide hydroxamic acid; PPAR $\gamma$, peroxisome proliferator-activated receptor $\gamma$; $M A P K$, mitogen-activated protein kinase; $R A F$, rapidly accelerated fibrosarcoma; MEK, MAPK kinase; PDGFR, platelet-derived growth factor receptors; HER, human epidermal growth factor receptor; PTEN, phosphatase and tensin homolog; mTOR, mechanistic target of rapamycin. 
pathway activation through HER3 activation was observed (65). BRAF or MEK inhibitors release transcription repressor proteins from the HER3 promoter and induce HER3 gene expression. HER expression was significantly increased in five of six thyroid cancer cell lines and increased HER3 activates PI3K and MAPK pathways (65). Combination therapy of BRAF/MEK inhibitors (dabrafenib/selumetinib) with a HER inhibitor (lapatinib) resulted in MAPK pathway suppression without a rebound phenomenon and increased NIS expression (75). A phase I study of dabrafenib in combination with lapatinib in BRAF-mutated thyroid cancer had been initiated (NCT01947023). If this study and the following phase II/III studies show promising results, the combined use of BRAF/MEK inhibitors with lapatinib could be a treatment option for patients with RR-DTC.

To overcome the rebound of MAPK signaling, an allosteric MEK inhibitor (CH5126766, known as CKI) could be a new candidate. CKI binds selectively to the non-phosphorylated form of MEK, and stabilizes RAF/MEK complex, which is inactive and stable. Thus, the CKI suppresses the feedback induction of MEK phosphorylation that occurs after ERK pathway inhibition in tumors exposed to other MEK inhibitors (76). Nagarajah et al. reported that CKI treatment restored NIS expression and radioiodine accumulation fivefold and twofold higher, respectively, than selumetinib treatment. Additionally, selumetinib or CKI treatment prior to radioiodine therapy significantly reduced tumor size compared to the effect of radioiodine therapy without pharmacological pretreatment in a mouse model (77).

Autophagy is a degradation machinery for recycling of intracellular content, and it plays important roles in cancer initiation and progression by influencing proliferation, differentiation and anticancer therapy resistance (78). Interestingly, loss of autophagy activity was shown to be associated with dedifferentiation of thyroid cancer and reduced clinical response to radioiodine therapy (79). PI3K/AKT/mechanistic target of rapamycin (mTOR) inhibitors, calcium channel antagonists, cAMP antagonists, inositol monophosphatase inhibitors, and other targets are considered as autophagy inducers (80).

The PI3K/AKT/mTOR pathway, which is related to downstream of RTK and autophagy activation, is a good therapeutic target for redifferentiation. PI3K acts as a negative regulator of NIS expression, and PTEN is an important positive regulator of NIS expression (Figure 1). miR-21 suppresses PTEN and acts as an oncogenic miR that antisense-miR-21 successfully increased NIS expression (81). The mTOR is considered as a key regulator of multiple downstream pathways that act on basic biological processes of protein synthesis, cell division, and cell death (82). Inhibiting mTOR induces radioiodine uptake through increased TTF1 expression $(83,84)$. Recently, several clinical trials have been performed to evaluate the effect of an mTOR inhibitor (everolimus) and the combined used of a TKI (sorafenib) and an mTOR inhibitor (temsirolimus) $(85,86)$. These clinical trials appear to be effective, but they did not evaluate the changes of radioiodine uptake and effectiveness of combined radioiodine therapy. Further clinical trials might be needed to elucidate the changes of radioiodine uptake and radioiodine treatment effect after suppression of PI3K/AKT/ mTOR pathway.
Tesselaar et al. demonstrated that digitalis-like compounds, also known as autophagy activators, restore NIS expression and iodide uptake in thyroid cancer cell lines (87). Upregulation of NIS was mediated by intracellular $\mathrm{Ca}^{2+}$ and FOS gene activation; FOS binds to the NIS upstream enhancer in conjunction with PAX8 (88). Schwertheim et al. showed potential role of curcumin to enhance the radioiodine therapy (89). Curcumin inhibits HDAC activity (90) and induces autophagy activation (91). Curcumin increased expression of thyroid-specific genes, such as NIS and thyroglobulin in thyroid cancer cell lines. And it reduced proliferation and induced apoptosis (89).

Gao et al. showed that inhibiting bromodomain-containing protein 4 (BRD4), which binds to acetylated histones, results in cell cycle arrest and enhanced radioiodine uptake in thyroid cancer cells (92). Singh et al. showed that inverse agonist of estrogenrelated receptor-gamma $(\mathrm{ERR} \gamma)$ enhances NIS expression and radioiodine uptake (93). However, BRD4 inhibitor and inverse agonist of ERR $\gamma$ need further studies to verify the mechanism of redifferentiation and evaluate optimal increase of radioiodine uptake in vivo.

\section{CONCLUSION}

Classic thyroid cancer redifferentiation agents such as RA, HDAC inhibitor, and PPAR gamma agonist have shown disappointing results in recent clinical trials. However, these studies did not perform tumor characterization, and appropriate selection of redifferentiation agents in each patient, using recently advanced knowledge about genetic and biological characteristics of thyroid cancer, might increase the effectiveness of redifferentiation treatment. Recent clinical trials showed promising results of RAF/MEK inhibitors for redifferentiation of RR-DTC; further verification of the results might change the paradigm of RR-DTC treatment. New target agents and combination use of drugs for redifferentiation in appropriately selected patients might enhance efficacy of radioiodine therapy and improve outcome of RR-DTC, which is refractory to conventional radioiodine treatment.

\section{REVIEW CRITERIA}

PubMed was searched for articles published from 1997 to July 2017 using the search terms "thyroid cancer," "redifferentiation," "retinoic acid," "PPAR," "HDAC," “TKI," “radioiodine," "I-131." Only English language, full-text papers were included. References found in these publications provided additional papers to search and cite.

\section{AUTHOR CONTRIBUTIONS}

Both $\mathrm{CH}$ and B-CA participated in drafting, writing, and editing the manuscript.

\section{FUNDING}

This work was supported by the National Research Foundation of Korea (NRF) grant funded by the Korea Government (MSIP) (No. NRF-2015M2A2A7A01045177). 


\section{REFERENCES}

1. Ahn BC. Sodium iodide symporter for nuclear molecular imaging and gene therapy: from bedside to bench and back. Theranostics (2012) 2(4):392-402. doi:10.7150/thno.3722

2. Oh JR, Ahn BC. False-positive uptake on radioiodine whole-body scintigraphy: physiologic and pathologic variants unrelated to thyroid cancer. Am J Nucl Med Mol Imaging (2012) 2(3):362-85.

3. Ahn BC. Nuclear medicine in the era of precision medicine. Nucl Med Mol Imaging (2017) 51(2):99-100. doi:10.1007/s13139-017-0478-5

4. Kim DH, Jung JH, Son SH, Kim CY, Hong CM, Jeong SY, et al. Difference of clinical and radiological characteristics according to radioiodine avidity in pulmonary metastases of differentiated thyroid cancer. $\mathrm{Nucl} \mathrm{Med} \mathrm{Mol}$ Imaging (2014) 48(1):55-62. doi:10.1007/s13139-013-0239-Z

5. Ahn BC. Personalized medicine based on theranostic radioiodine molecular imaging for differentiated thyroid cancer. Biomed Res Int (2016) 2016:1680464. doi:10.1155/2016/1680464

6. Chung JK, Youn HW, Kang JH, Lee HY, Kang KW. Sodium iodide symporter and the radioiodine treatment of thyroid carcinoma. Nucl Med Mol Imaging (2010) 44(1):4-14. doi:10.1007/s13139-009-0016-1

7. Sampson E, Brierley JD, Le LW, Rotstein L, Tsang RW. Clinical management and outcome of papillary and follicular (differentiated) thyroid cancer presenting with distant metastasis at diagnosis. Cancer (2007) 110(7):1451-6. doi:10.1002/cncr.22956

8. Hong CM, Lee WK, Jeong SY, Lee SW, Ahn BC, Lee J. Superiority of delayed risk stratification in differentiated thyroid cancer after total thyroidectomy and radioactive iodine ablation. Nucl Med Commun (2014) 35(11):1119-26. doi:10.1097/MNM.0000000000000183

9. Durante C, Haddy N, Baudin E, Leboulleux S, Hartl D, Travagli JP, et al. Long-term outcome of 444 patients with distant metastases from papillary and follicular thyroid carcinoma: benefits and limits of radioiodine therapy. J Clin Endocrinol Metab (2006) 91(8):2892-9. doi:10.1210/jc.2005-2838

10. Hong CM, Ahn BC, Jeong SY, Lee SW, Lee J. Distant metastatic lesions in patients with differentiated thyroid carcinoma. Clinical implications of radioiodine and FDG uptake. Nuklearmedizin (2013) 52(4):121-9. doi:10.3413/ Nukmed-0541-12-11

11. Haugen BR, Alexander EK, Bible KC, Doherty GM, Mandel SJ, Nikiforov YE, et al. 2015 American Thyroid Association Management Guidelines for adult patients with thyroid nodules and differentiated thyroid cancer: the American Thyroid Association Guidelines Task Force on thyroid nodules and differentiated thyroid cancer. Thyroid (2016) 26(1):1-133. doi:10.1089/thy.2015.0020

12. Ho AL, Grewal RK, Leboeuf R, Sherman EJ, Pfister DG, Deandreis D, et al. Selumetinib-enhanced radioiodine uptake in advanced thyroid cancer. N Engl J Med (2013) 368(7):623-32. doi:10.1056/NEJMoa1209288

13. Brose MS, Nutting CM, Jarzab B, Elisei R, Siena S, Bastholt L, et al. Sorafenib in radioactive iodine-refractory, locally advanced or metastatic differentiated thyroid cancer: a randomised, double-blind, phase 3 trial. Lancet (2014) 384(9940):319-28. doi:10.1016/S0140-6736(14)60421-9

14. Schlumberger M, Tahara M, Wirth LJ, Robinson B, Brose MS, Elisei R, et al. Lenvatinib versus placebo in radioiodine-refractory thyroid cancer. $N$ Engl J Med (2015) 372(7):621-30. doi:10.1056/NEJMoa1406470

15. Cancer Genome Atlas Research Network. Integrated genomic characterization of papillary thyroid carcinoma. Cell (2014) 159(3):676-90. doi:10.1016/j. cell.2014.09.050

16. Chakravarty D, Santos E, Ryder M, Knauf JA, Liao XH, West BL, et al. Small-molecule MAPK inhibitors restore radioiodine incorporation in mouse thyroid cancers with conditional BRAF activation. J Clin Invest (2011) 121(12):4700-11. doi:10.1172/JCI46382

17. Fagin JA, Wells SA Jr. Biologic and clinical perspectives on thyroid cancer. N Engl J Med (2016) 375(11):1054-67. doi:10.1056/NEJMra1501993

18. Paeng JC, Kang KW, Park DJ, Oh SW, Chung JK. Alternative medical treatment for radioiodine-refractory thyroid cancers. Nucl Med Mol Imaging (2011) 45(4):241-7. doi:10.1007/s13139-011-0107-7

19. Grewal RK, Ho A, Schoder H. Novel approaches to thyroid cancer treatment and response assessment. Semin Nucl Med (2016) 46(2):109-18. doi:10.1053/j. semnuclmed.2015.10.010

20. Valerio L, Pieruzzi L, Giani C, Agate L, Bottici V, Lorusso L, et al. Targeted therapy in thyroid cancer: state of the art. Clin Oncol (R Coll Radiol) (2017) 29(5):316-24. doi:10.1016/j.clon.2017.02.009
21. Rothenberg SM, McFadden DG, Palmer EL, Daniels GH, Wirth LJ. Redifferentiation of iodine-refractory BRAF V600E-mutant metastatic papillary thyroid cancer with dabrafenib. Clin Cancer Res (2015) 21(5):1028-35. doi:10.1158/1078-0432.CCR-14-2915

22. Schmutzler C, Schmitt TL, Glaser F, Loos U, Kohrle J. The promoter of the human sodium/iodide-symporter gene responds to retinoic acid. Mol Cell Endocrinol (2002) 189(1-2):145-55. doi:10.1016/S0303-7207(01)00735-3

23. Kim WG, Kim EY, Kim TY, Ryu JS, Hong SJ, Kim WB, et al. Redifferentiation therapy with 13-cis retinoic acids in radioiodine-resistant thyroid cancer. Endocr J (2009) 56(1):105-12. doi:10.1507/endocrj.K08E-254

24. Simon D, Kohrle J, Schmutzler C, Mainz K, Reiners C, Roher HD. Redifferentiation therapy of differentiated thyroid carcinoma with retinoic acid: basics and first clinical results. Exp Clin Endocrinol Diabetes (1996) 104(Suppl 4):13-5. doi:10.1055/s-0029-1211692

25. Grunwald F, Menzel C, Bender H, Palmedo H, Otte R, Fimmers R, et al. Redifferentiation therapy-induced radioiodine uptake in thyroid cancer. J Nucl Med (1998) 39(11):1903-6.

26. Simon D, Koehrle J, Reiners C, Boerner AR, Schmutzler C, Mainz K, et al. Redifferentiation therapy with retinoids: therapeutic option for advanced follicular and papillary thyroid carcinoma. World J Surg (1998) 22(6):569-74. doi:10.1007/s002689900436

27. Simon D, Korber C, Krausch M, Segering J, Groth P, Gorges R, et al. Clinical impact of retinoids in redifferentiation therapy of advanced thyroid cancer: final results of a pilot study. Eur J Nucl Med Mol Imaging (2002) 29(6):775-82. doi:10.1007/s00259-001-0737-6

28. Fernandez CA, Puig-Domingo M, Lomena F, Estorch M, Camacho Marti V, Bittini AL, et al. Effectiveness of retinoic acid treatment for redifferentiation of thyroid cancer in relation to recovery of radioiodine uptake. J Endocrinol Invest (2009) 32(3):228-33. doi:10.1007/BF03346457

29. Oh SW, Moon SH, Park DJ, Cho BY, Jung KC, Lee DS, et al. Combined therapy with $131 \mathrm{I}$ and retinoic acid in Korean patients with radioiodine-refractory papillary thyroid cancer. Eur J Nucl Med Mol Imaging (2011) 38(10):1798-805. doi:10.1007/s00259-011-1849-2

30. Gruning T, Tiepolt C, Zophel K, Bredow J, Kropp J, Franke WG. Retinoic acid for redifferentiation of thyroid cancer - does it hold its promise? Eur J Endocrinol (2003) 148(4):395-402. doi:10.1530/eje.0.1480395

31. Short SC, Suovuori A, Cook G, Vivian G, Harmer C. A phase II study using retinoids as redifferentiation agents to increase iodine uptake in metastatic thyroid cancer. Clin Oncol (R Coll Radiol) (2004) 16(8):569-74. doi:10.1016/j. clon.2004.06.018

32. Courbon F, Zerdoud S, Bastie D, Archambaud F, Hoff M, Eche N, et al. Defective efficacy of retinoic acid treatment in patients with metastatic thyroid carcinoma. Thyroid (2006) 16(10):1025-31. doi:10.1089/thy.2006.16.1025

33. Handkiewicz-Junak D, Roskosz J, Hasse-Lazar K, Szpak-Ulczok S, Puch Z, Kukulska A, et al. 13-cis-retinoic acid re-differentiation therapy and recombinant human thyrotropin-aided radioiodine treatment of non-functional metastatic thyroid cancer: a single-center, 53-patient phase 2 study. Thyroid Res (2009) 2(1):8. doi:10.1186/1756-6614-2-8

34. Zhang Y, Jia S, Liu Y, Li B, Wang Z, Lu H, et al. A clinical study of all-transretinoid-induced differentiation therapy of advanced thyroid cancer. $\mathrm{Nucl}$ Med Commun (2007) 28(4):251-5. doi:10.1097/MNM.0b013e3280708ebf

35. Teixeira C, Pratt MA. CDK2 is a target for retinoic acid-mediated growth inhibition in MCF-7 human breast cancer cells. Mol Endocrinol (1997) 11(9):1191-202. doi:10.1210/mend.11.9.9977

36. Sun SY, Yue P, Wu GS, El-Deiry WS, Shroot B, Hong WK, et al. Mechanisms of apoptosis induced by the synthetic retinoid CD437 in human non-small cell lung carcinoma cells. Oncogene (1999) 18(14):2357-65. doi:10.1038/ sj.onc. 1202543

37. Liu YY, Stokkel MP, Pereira AM, Corssmit EP, Morreau HA, Romijn JA, et al. Bexarotene increases uptake of radioiodide in metastases of differentiated thyroid carcinoma. Eur J Endocrinol (2006) 154(4):525-31. doi:10.1530/ eje. 1.02123

38. Catalano MG, Fortunati N, Pugliese M, Costantino L, Poli R, Bosco O, et al. Valproic acid induces apoptosis and cell cycle arrest in poorly differentiated thyroid cancer cells. J Clin Endocrinol Metab (2005) 90(3):1383-9. doi:10.1210/ jc.2004-1355

39. Kitazono M, Robey R, Zhan Z, Sarlis NJ, Skarulis MC, Aikou T, et al. Low concentrations of the histone deacetylase inhibitor, depsipeptide (FR901228), increase expression of the $\mathrm{Na}(+) / \mathrm{I}(-)$ symporter and iodine accumulation in 
poorly differentiated thyroid carcinoma cells. J Clin Endocrinol Metab (2001) 86(7):3430-5. doi:10.1210/jcem.86.7.7621

40. Furuya F, Shimura H, Suzuki H, Taki K, Ohta K, Haraguchi K, et al. Histone deacetylase inhibitors restore radioiodide uptake and retention in poorly differentiated and anaplastic thyroid cancer cells by expression of the sodium/ iodide symporter thyroperoxidase and thyroglobulin. Endocrinology (2004) 145(6):2865-75. doi:10.1210/en.2003-1258

41. Xu J, Hershman JM. Histone deacetylase inhibitor depsipeptide represses nicotinamide N-methyltransferase and hepatocyte nuclear factor-1beta gene expression in human papillary thyroid cancer cells. Thyroid (2006) 16(2):151-60. doi:10.1089/thy.2006.16.151

42. Zarnegar R, Brunaud L, Kanauchi H, Wong M, Fung M, Ginzinger D, et al. Increasing the effectiveness of radioactive iodine therapy in the treatment of thyroid cancer using Trichostatin A, a histone deacetylase inhibitor. Surgery (2002) 132(6):984-90; discussion 990. doi:10.1067/msy.2002.128690

43. Fortunati N, Catalano MG, Arena K, Brignardello E, Piovesan A, Boccuzzi G. Valproic acid induces the expression of the Na+/I- symporter and iodine uptake in poorly differentiated thyroid cancer cells. J Clin Endocrinol Metab (2004) 89(2):1006-9. doi:10.1210/jc.2003-031407

44. Puppin C, D'Aurizio F, D'Elia AV, Cesaratto L, Tell G, Russo D, et al. Effects of histone acetylation on sodium iodide symporter promoter and expression of thyroid-specific transcription factors. Endocrinology (2005) 146(9):3967-74. doi:10.1210/en.2005-0128

45. Hou P, Bojdani E, Xing M, et al. Induction of thyroid gene expression and radioiodine uptake in thyroid cancer cells by targeting major signaling pathways. J Clin Endocrinol Metab (2010) 95(2):820-8. doi:10.1210/jc.2009-1888

46. Kelly WK, O'Connor OA, Krug LM, Chiao JH, Heaney M, Curley T, et al. Phase I study of an oral histone deacetylase inhibitor, suberoylanilide hydroxamic acid, in patients with advanced cancer. J Clin Oncol (2005) 23(17):3923-31. doi:10.1200/JCO.2005.14.167

47. Amiri-Kordestani L, Luchenko V, Peer CJ, Ghafourian K, Reynolds J, Draper D, et al. Phase I trial of a new schedule of romidepsin in patients with advanced cancers. Clin Cancer Res (2013) 19(16):4499-507. doi:10.1158/10780432.CCR-13-0095

48. Sherman EJ, Su YB, Lyall A, Schoder H, Fury MG, Ghossein RA, et al. Evaluation of romidepsin for clinical activity and radioactive iodine reuptake in radioactive iodine-refractory thyroid carcinoma. Thyroid (2013) 23(5):593-9. doi:10.1089/thy.2012.0393

49. Nilubol N, Merkel R, Yang L, Patel D, Reynolds JC, Sadowski SM, et al. A phase II trial of valproic acid in patients with advanced, radioiodineresistant thyroid cancers of follicular cell origin. Clin Endocrinol (Oxf) (2017) 86(1):128-33. doi:10.1111/cen.13154

50. Hayashi N, Nakamori S, Hiraoka N, Tsujie M, Xundi X, Takano T, et al. Antitumor effects of peroxisome proliferator activate receptor gamma ligands on anaplastic thyroid carcinoma. Int J Oncol (2004) 24(1):89-95. doi:10.3892/ ijo.24.1.89

51. Karger S, Berger K, Eszlinger M, Tannapfel A, Dralle H, Paschke R, et al. Evaluation of peroxisome proliferator-activated receptor-gamma expression in benign and malignant thyroid pathologies. Thyroid (2005) 15(9):997-1003. doi:10.1089/thy.2005.15.997

52. Martelli ML, Iuliano R, Le Pera I, Sama I, Monaco C, Cammarota S, et al. Inhibitory effects of peroxisome proliferator-activated receptor gamma on thyroid carcinoma cell growth. JClin Endocrinol Metab (2002) 87(10):4728-35. doi:10.1210/jc.2001-012054

53. Frohlich E, Machicao F, Wahl R. Action of thiazolidinediones on differentiation, proliferation and apoptosis of normal and transformed thyrocytes in culture. Endocr Relat Cancer (2005) 12(2):291-303. doi:10.1677/erc.1.00973

54. Park JW, Zarnegar R, Kanauchi H, Wong MG, Hyun WC, Ginzinger DG, et al. Troglitazone, the peroxisome proliferator-activated receptor-gamma agonist, induces antiproliferation and redifferentiation in human thyroid cancer cell lines. Thyroid (2005) 15(3):222-31. doi:10.1089/thy.2005.15.222

55. Philips JC, Petite C, Willi JP, Buchegger F, Meier CA. Effect of peroxisome proliferator-activated receptor gamma agonist, rosiglitazone, on dedifferentiated thyroid cancers. Nucl Med Commun (2004) 25(12):1183-6. doi:10.1097/00006231-200412000-00005

56. Kebebew E, Lindsay S, Clark OH, Woeber KA, Hawkins R, Greenspan FS. Results of rosiglitazone therapy in patients with thyroglobulin-positive and radioiodine-negative advanced differentiated thyroid cancer. Thyroid (2009) 19(9):953-6. doi:10.1089/thy.2008.0371
57. Tepmongkol S, Keelawat S, Honsawek S, Ruangvejvorachai P. Rosiglitazone effect on radioiodine uptake in thyroid carcinoma patients with high thyroglobulin but negative total body scan: a correlation with the expression of peroxisome proliferator-activated receptor-gamma. Thyroid (2008) 18(7):697-704. doi:10.1089/thy.2008.0056

58. Kebebew E, Peng M, Reiff E, Treseler P, Woeber KA, Clark OH, et al. A phase II trial of rosiglitazone in patients with thyroglobulin-positive and radioiodine-negative differentiated thyroid cancer. Surgery (2006) 140(6):960-6; discussion 966-67. doi:10.1016/j.surg.2006.07.038

59. Kroll TG, Sarraf P, Pecciarini L, Chen CJ, Mueller E, Spiegelman BM, et al. PAX8-PPARgammal fusion oncogene in human thyroid carcinoma [corrected]. Science (2000) 289(5483):1357-60. doi:10.1126/science.289. 5483.1357

60. Castro P, Rebocho AP, Soares RJ, Magalhaes J, Roque L, Trovisco V, et al. PAX8PPARgamma rearrangement is frequently detected in the follicular variant of papillary thyroid carcinoma. J Clin Endocrinol Metab (2006) 91(1):213-20. doi:10.1210/jc.2005-1336

61. Ferrari SM, Materazzi G, Baldini E, Ulisse S, Miccoli P, Antonelli A, et al. Antineoplastic effects of PPARgamma agonists, with a special focus on thyroid cancer. Curr Med Chem (2016) 23(7):636-49. doi:10.2174/ 0929867323666160203114607

62. Dobson ME, Diallo-Krou E, Grachtchouk V, Yu J, Colby LA, Wilkinson JE, et al. Pioglitazone induces a proadipogenic antitumor response in mice with PAX8-PPARgamma fusion protein thyroid carcinoma. Endocrinology (2011) 152(11):4455-65. doi:10.1210/en.2011-1178

63. Raman P, Koenig RJ. Pax-8-PPAR-gamma fusion protein in thyroid carcinoma. Nat Rev Endocrinol (2014) 10(10):616-23. doi:10.1038/nrendo.2014.115

64. Wang W, Larson SM, Tuttle RM, Kalaigian H, Kolbert K, Sonenberg M, et al. Resistance of [18f]-fluorodeoxyglucose-avid metastatic thyroid cancer lesions to treatment with high-dose radioactive iodine. Thyroid (2001) 11(12):1169-75. doi:10.1089/10507250152741028

65. Montero-Conde C, Ruiz-Llorente S, Dominguez JM, Knauf JA, Viale A, Sherman EJ, et al. Relief of feedback inhibition of HER3 transcription by RAF and MEK inhibitors attenuates their antitumor effects in BRAF-mutant thyroid carcinomas. Cancer Discov (2013) 3(5):520-33. doi:10.1158/2159-8290. CD-12-0531

66. Newbold KL, Flux G, Wadsley J. Radioiodine for high risk and radioiodine refractory thyroid cancer: current concepts in management. Clin Oncol (R Coll Radiol) (2017) 29(5):307-9. doi:10.1016/j.clon.2016.12.008

67. Deandreis D, Rubino C, Tala H, Leboulleux S, Terroir M, Baudin E, et al. Comparison of empiric versus whole-body/-blood clearance dosimetry-based approach to radioactive iodine treatment in patients with metastases from differentiated thyroid cancer. J Nucl Med (2017) 58(5):717-22. doi:10.2967/ jnumed.116.179606

68. Jentzen W, Nahum AE, Bockisch A, Binse I, Tulchinsky M. Fixed 3.7-GBq 131I Activity for Metastatic Thyroid Cancer Therapy Ignores Science and History. J Nucl Med (2017) 58(9):1530. doi:10.2967/jnumed.117.192872

69. Jentzen W, Freudenberg L, Eising EG, Sonnenschein W, Knust J, Bockisch A. Optimized 124I PET dosimetry protocol for radioiodine therapy of differentiated thyroid cancer. J Nucl Med (2008) 49(6):1017-23. doi:10.2967/ jnumed.107.047159

70. Hong CM, Kim CY, Son SH, Jung JH, Lee CH, Jeong JH, et al. I-131 biokinetics of remnant normal thyroid tissue and residual thyroid cancer in patients with differentiated thyroid cancer: comparison between recombinant human TSH administration and thyroid hormone withdrawal. Ann Nucl Med (2017) 31(8):582-9. doi:10.1007/s12149-017-1188-x

71. Lee SW. SPECT/CT in the treatment of differentiated thyroid cancer. Nucl Med Mol Imaging (2017). doi:10.1007/s13139-017-0473-x

72. Bible KC, Ryder M. Evolving molecularly targeted therapies for advancedstage thyroid cancers. Nat Rev Clin Oncol (2016) 13(7):403-16. doi:10.1038/ nrclinonc.2016.19

73. Lopez-Campistrous A, Adewuyi EE, Benesch MG, Ko YM, Lai R, Thiesen A, et al. PDGFRalpha regulates follicular cell differentiation driving treatment resistance and disease recurrence in papillary thyroid cancer. EBioMedicine (2016) 12:86-97. doi:10.1016/j.ebiom.2016.09.007

74. Larson SM, Osborne JR, Grewal RK, Tuttle RM. Redifferentiating thyroid cancer: selumetinib-enhanced radioiodine uptake in thyroid cancer. Mol Imaging Radionucl Ther (2017) 26(Suppl 1):80-6. doi:10.4274/2017.26. suppl.09 
75. Cheng L, Jin Y, Liu M, Ruan M, Chen L. HER inhibitor promotes BRAF/ MEK inhibitor-induced redifferentiation in papillary thyroid cancer harboring BRAFV600E. Oncotarget (2017) 8(12):19843-54. doi:10.18632/ oncotarget.15773

76. Ishii N, Harada N, Joseph EW, Ohara K, Miura T, Sakamoto H, et al. Enhanced inhibition of ERK signaling by a novel allosteric MEK inhibitor, CH5126766, that suppresses feedback reactivation of RAF activity. Cancer Res (2013) 73(13):4050-60. doi:10.1158/0008-5472.CAN-12-3937

77. Nagarajah J, Le M, Knauf JA, Ferrandino G, Montero-Conde C, Pillarsetty N, et al. Sustained ERK inhibition maximizes responses of BrafV600E thyroid cancers to radioiodine. J Clin Invest (2016) 126(11):4119-24. doi:10.1172/ JCI89067

78. Choi AM, Ryter SW, Levine B. Autophagy in human health and disease. NEngl J Med (2013) 368(7):651-62. doi:10.1056/NEJMra1205406

79. Plantinga TS, Tesselaar MH, Morreau H, Corssmit EP, Willemsen BK, Kusters B, et al. Autophagy activity is associated with membranous sodium iodide symporter expression and clinical response to radioiodine therapy in non-medullary thyroid cancer. Autophagy (2016) 12(7):1195-205. doi:10.1080/ 15548627.2016.1174802

80. Rubinsztein DC, Codogno P, Levine B. Autophagy modulation as a potential therapeutic target for diverse diseases. Nat Rev Drug Discov (2012) 11(9):709-30. doi:10.1038/nrd3802

81. Haghpanah V, Fallah P, Tavakoli R, Naderi M, Samimi H, Soleimani M, et al. Antisense-miR-21 enhances differentiation/apoptosis and reduces cancer stemness state on anaplastic thyroid cancer. Tumour Biol (2016) 37(1):1299-308. doi:10.1007/s13277-015-3923-z

82. Laplante M, Sabatini DM. mTOR signaling in growth control and disease. Cell (2012) 149(2):274-93. doi:10.1016/j.cell.2012.03.017

83. de Souza EC, Padron AS, Braga WM, de Andrade BM, Vaisman M, Nasciutti LE, et al. MTOR downregulates iodide uptake in thyrocytes. J Endocrinol (2010) 206(1):113-20. doi:10.1677/JOE-09-0436

84. Plantinga TS, Heinhuis B, Gerrits D, Netea MG, Joosten LA, Hermus AR, et al. mTOR Inhibition promotes TTF1-dependent redifferentiation and restores iodine uptake in thyroid carcinoma cell lines. J Clin Endocrinol Metab (2014) 99(7):E1368-75. doi:10.1210/jc.2014-1171

85. SchneiderTC, de Wit D, Links TP, van Erp NP, van der Hoeven JJ, Gelderblom $H$, et al. Everolimus in patients with advanced follicular-derived thyroid cancer: results of a phase II clinical trial. J Clin Endocrinol Metab (2017) 102(2):698-707. doi:10.1210/jc.2016-2525

86. Sherman EJ, Dunn LA, Ho AL, Baxi SS, Ghossein RA, Fury MG, et al. Phase 2 study evaluating the combination of sorafenib and temsirolimus in the treatment of radioactive iodine-refractory thyroid cancer. Cancer (2017). doi:10.1002/cncr.30861
87. Tesselaar MH, Crezee T, Swarts HG, Gerrits D, Boerman OC, Koenderink JB et al. Digitalis-like compounds facilitate non-medullary thyroid cancer redifferentiation through intracellular $\mathrm{Ca} 2+, \mathrm{FOS}$, and autophagy-dependent pathways. Mol Cancer Ther (2017) 16(1):169-81. doi:10.1158/1535-7163. MCT-16-0460

88. Chun JT, Di Dato V, D’Andrea B, Zannini M, Di Lauro R. The CRE-like element inside the 5 '-upstream region of the rat sodium/iodide symporter gene interacts with diverse classes of b-Zip molecules that regulate transcriptional activities through strong synergy with Pax-8. Mol Endocrinol (2004) 18(11):2817-29. doi:10.1210/me.2004-0020

89. Schwertheim S, Wein F, Lennartz K, Worm K, Schmid KW, Sheu-Grabellus SY. Curcumin induces G2/M arrest, apoptosis, NF-kappaB inhibition, and expression of differentiation genes in thyroid carcinoma cells. J Cancer Res Clin Oncol (2017) 143(7):1143-54. doi:10.1007/s00432-017-2380-z

90. Teiten MH, Dicato M, Diederich M. Curcumin as a regulator of epigenetic events. Mol Nutr Food Res (2013) 57(9):1619-29. doi:10.1002/mnfr. 201300201

91. Moustapha A, Peretout PA, Rainey NE, Sureau F, Geze M, Petit JM, et al. Curcumin induces crosstalk between autophagy and apoptosis mediated by calcium release from the endoplasmic reticulum, lysosomal destabilization and mitochondrial events. Cell Death Discov (2015) 1:15017. doi:10.1038/ cddiscovery.2015.17

92. Gao X, Wu X, Zhang X, Hua W, Zhang Y, Maimaiti Y, et al. Inhibition of BRD4 suppresses tumor growth and enhances iodine uptake in thyroid cancer. Biochem Biophys Res Commun (2016) 469(3):679-85. doi:10.1016/j. bbrc.2015.12.008

93. Singh TD, Jeong SY, Lee SW, Ha JH, Lee IK, Kim SH, et al. Inverse agonist of estrogen-related receptor gamma enhances sodium iodide symporter function through mitogen-activated protein kinase signaling in anaplastic thyroid cancer cells. J Nucl Med (2015) 56(11):1690-6. doi:10.2967/jnumed. 115.160366

Conflict of Interest Statement: The authors declare that the research was conducted in the absence of any commercial or financial relationships that could be construed as a potential conflict of interest.

Copyright (C) 2017 Hong and Ahn. This is an open-access article distributed under the terms of the Creative Commons Attribution License (CC BY). The use, distribution or reproduction in other forums is permitted, provided the original author(s) or licensor are credited and that the original publication in this journal is cited, in accordance with accepted academic practice. No use, distribution or reproduction is permitted which does not comply with these terms. 